\title{
La vivienda como proceso. Estrategias de flexibilidad*
}

\author{
Eva Morales Soler y Rubén Alonso Mallén ** \\ Esperanza Moreno Cruz ${ }^{* * *}$
}

\section{Resumen}

La vivienda es el espacio donde principalmente encontramos nuestra privacidad y donde desarrollamos una parte importante de las actividades básicas de nuestro quehacer cotidiano. En contraste con esto, en las últimas décadas en España la vivienda se ha convertido en el principal motor especulativo de la economía, y ha dejado de atender en gran medida su función social de generar hábitat digno a la ciudadanía. Llegados a este punto, vemos necesario revisar el paradigma en el que se concibe la vivienda, para entenderla no tanto como un objeto que se termina en un momento determinado, sino como un proceso que va transformándose y adoptando diferentes configuraciones espaciales a lo largo del tiempo. Para ello se propone abordar la vivienda como un ecosistema donde interaccionan la flexibilidad espacial, la participación y organización de la ciudadanía y la gestión de la misma. Nos centramos en las estrategias de flexibilidad y en el diseño tipológico que permiten la adaptación de la vivienda a las necesidades cambiantes de las personas usuarias, posibilitando su personalización, interacción y participación a lo largo de la vida útil de esta. En este sentido, la recopilación de experiencias previas se hace imprescindible para recuperar lo aprendido en procesos colectivos de vivienda desarrollados en otros contextos, y aprender de las buenas prácticas que nos ofrecen los referentes seleccionados. Se busca así una visión integral y holística de la vivienda que genere una mejora en el acceso, habitabilidad y bienestar de la ciudadanía, en los espacios que habita y con proyección en el tiempo.

\section{Palabras clave}

Vivienda; Participación Ciudadana; Flexibilidad; Procesos Colectivos

\section{Abstract: The house as a process. Flexibility strategies}

The house is the space where we mainly find our privacy and where we undertake a significant part of the basic activities of our daily lives. However, over recent decades in Spain the house has become the main speculative motor of the economy, and has, to a great extent, ceased in its social function of generating a decent habitat for the citizenry.

At this point, we see the need to review the paradigm in which the house is conceived, to understand it not so much as an object that is finished, at a certain moment, but as a process which transforms it, adopting different spatial configurations over time. To this end it is proposed to approach the house as an ecosystem whereby its management, spatial flexibility, and the participation and organisation of the citizenry all interact. We focus on the flexibility strategies and the types of design that allow the house to be adapted to the changing needs of the users, enabling their interaction and participation by customizing it throughout its useful life. In this sense, it is essential to compile previous experiences to recover what has been learned in group processes of housing developed in other contexts, and to learn from the good practices offered to us by the selected examples. Thus, a comprehensive and holistic vision of housing is sought which generates an improvement in the access, habitability and citizen well-being, in the spaces in which they live and with projection in time

\footnotetext{
Recibido: 16/07/2012; aceptado definitivamente: 24/01/2013

*Artículo basado en el proyecto de investigación "casa más o menos: la vivienda como proceso" de lapanaderia. arquitectura y diseño. S.L.P. Subvencionado por la Consejería de Vivienda y Ordenación del Territorio. Junta de Andalucía. 2010. Para conocer más experiencias de las que aquí relatamos: http://investigacion.casamasomenos.net.

** Arquitectos. Socios de lapanadería. www.despachodepan.com. info@despachodepan.com. Profesores Asociados de la Escuela de Arquitectura de la Universidad de Málaga

*** Arquitecta
} 


\section{Key words}

Housing; Citizen Participation; Flexibility; Group Processes

\section{Introducción: Políticas habitacionales y modelos sociales}

La situación en la que se encuentra el sector de la vivienda en España es en gran medida resultado de políticas económicas y fiscales de las últimas décadas. El objetivo principal de estas políticas ha sido convertir al sector de la construcción en el agente dinamizador de la actividad económica y relegar abiertamente el derecho ciudadano al acceso a una vivienda para favorecer la especulación inmobiliaria. En España se ha puesto en juego el valor de uso de la vivienda, en beneficio de su valor de cambio, en el que la política habitacional ha tendido a considerarla como un bien de inversión, a tener en propiedad, orientado a sostener un crecimiento económico irracional y poco sostenible, y cuyo fin no ha sido más que transformarse en un objeto de acumulación.

Por otro lado, a partir de los años sesenta se han producido muchos cambios y muy rápidos en los modelos sociales, que han provocado, junto con otros cambios económicos y demográficos, transformaciones en los modelos de las familias existentes y sus formas de comportamiento: se rompe el modelo de familia tradicional, concebido como familia nuclear amplia, extensa y de relaciones complejas; pasando a un modelo más pequeño, y simple, donde se produce una disolución del núcleo familiar, surgiendo un modelo de familia mínima, individual y privada.

Estos cambios repercuten directamente en la vivienda, entendida ésta como el primer espacio de sociabilidad y representación espacial de las diversas agrupaciones familiares, por lo que se le exige una adaptación a las diversas maneras de vivir de la sociedad y adecuarse a estas nuevas demandas sociales.

Aunque a lo largo de los años las viviendas han ido adaptándose progresivamente a los cambios culturales, económicos y sociales que en las familias se han ido produciendo, en este momento se hace difícil la reconfiguración de los conceptos de hogar debido al ritmo vertiginoso en que estos cambios se están produciendo y el poco cuestionamiento que se ha realizado de los modelos dominantes de hacer vivienda.

\section{Necesidades sociales en relación a la vivienda}

La necesidad de personalizar la vivienda del ser humano está directamente relacionada con la de apropiarse y transformar su entorno. Para Heidegger habitar es la manera en la que los seres humanos pertenecen, se relacionan con el mundo y por tanto son. Heidegger establece que el habitar está directamente conectado a todo acto de construcción. Construir no es únicamente el proceso de hacer edificios, no es un medio que nos permite posteriormente habitar, construir es en sí mismo habitar, ya que es el medio principal por el que los seres humanos nos relacionamos con el mundo y formamos parte de él (Heidegger, 2001). Podemos afirmar que la vida privada no es estándar, uniforme, homogénea ni estable, por lo que sólo un sistema que se ajuste a los cambios puede resultar confortable. Por este motivo, no se puede aislar la definición del confort del sentido propio de la vivienda. Las distintas necesidades que van surgiendo a lo largo de la vida de las personas pueden llegar a requerir una adaptación del espacio en el que viven, para poder seguir 


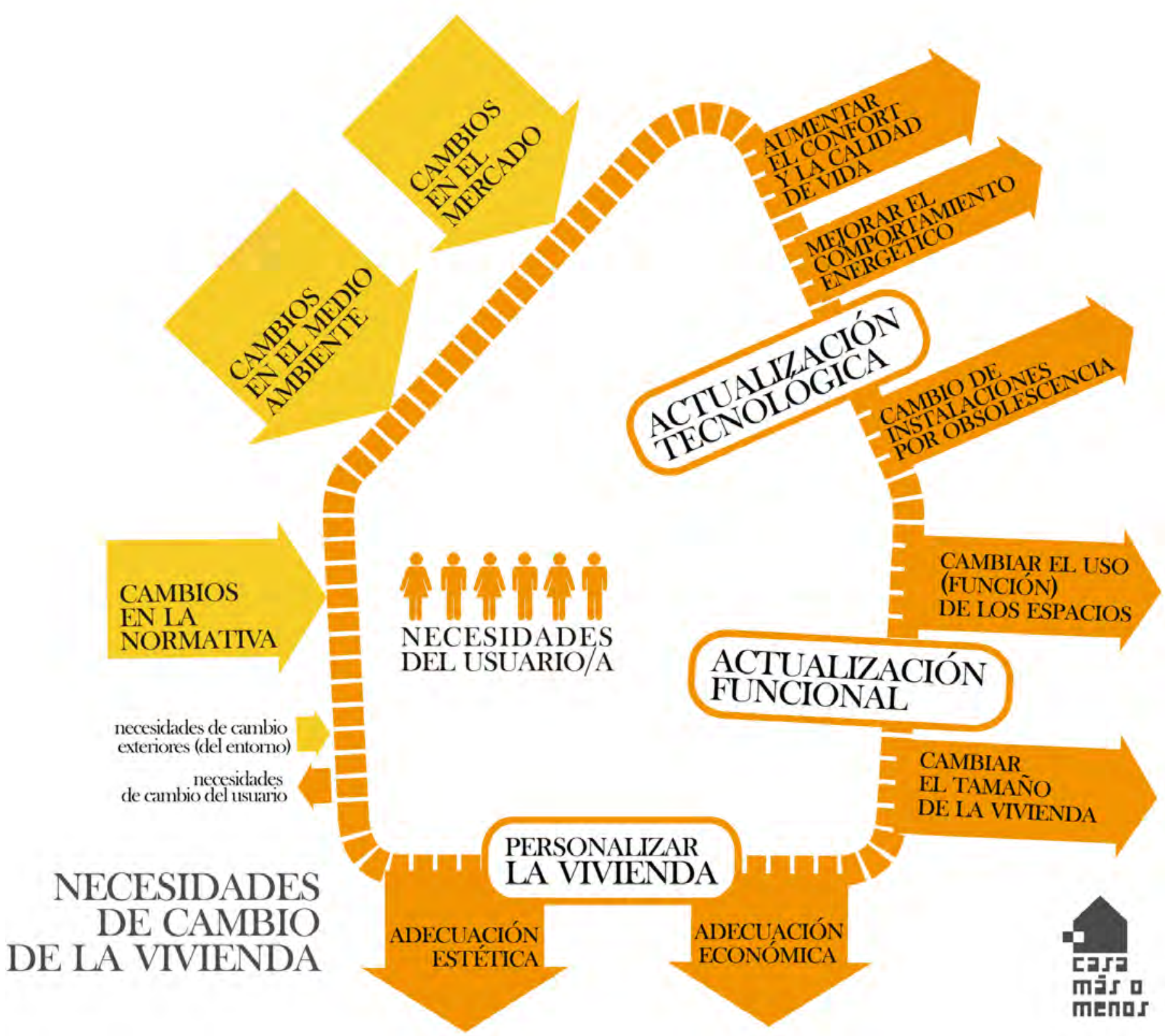

Figura 1. Necesidades de cambio de la vivienda. Fuente: Elaboración propia.

habitando en él en condiciones de habitabilidad adecuadas, ajustadas a su economía, al uso de los espacios, al gasto de recursos energéticos y al entorno en el que esté ubicada la propia vivienda.

Las necesidades de cambio de la vivienda vienen por lo tanto de la necesidad de personalizar la vivienda, de actualizarla tecnológica y funcionalmente. Por otro lado, las necesidades de transformación no sólo proceden de las necesidades de las personas, sino que también pueden proce- der del entorno en el que se inserta la vivienda, tales como cambios en las normativas, en el mercado, en el medio ambiente o en las propias estrategias políticas.

\section{La vivienda como objeto frente a vivienda como proceso}

La consideración de la vivienda como un objeto terminado es la más habitual y la que se 


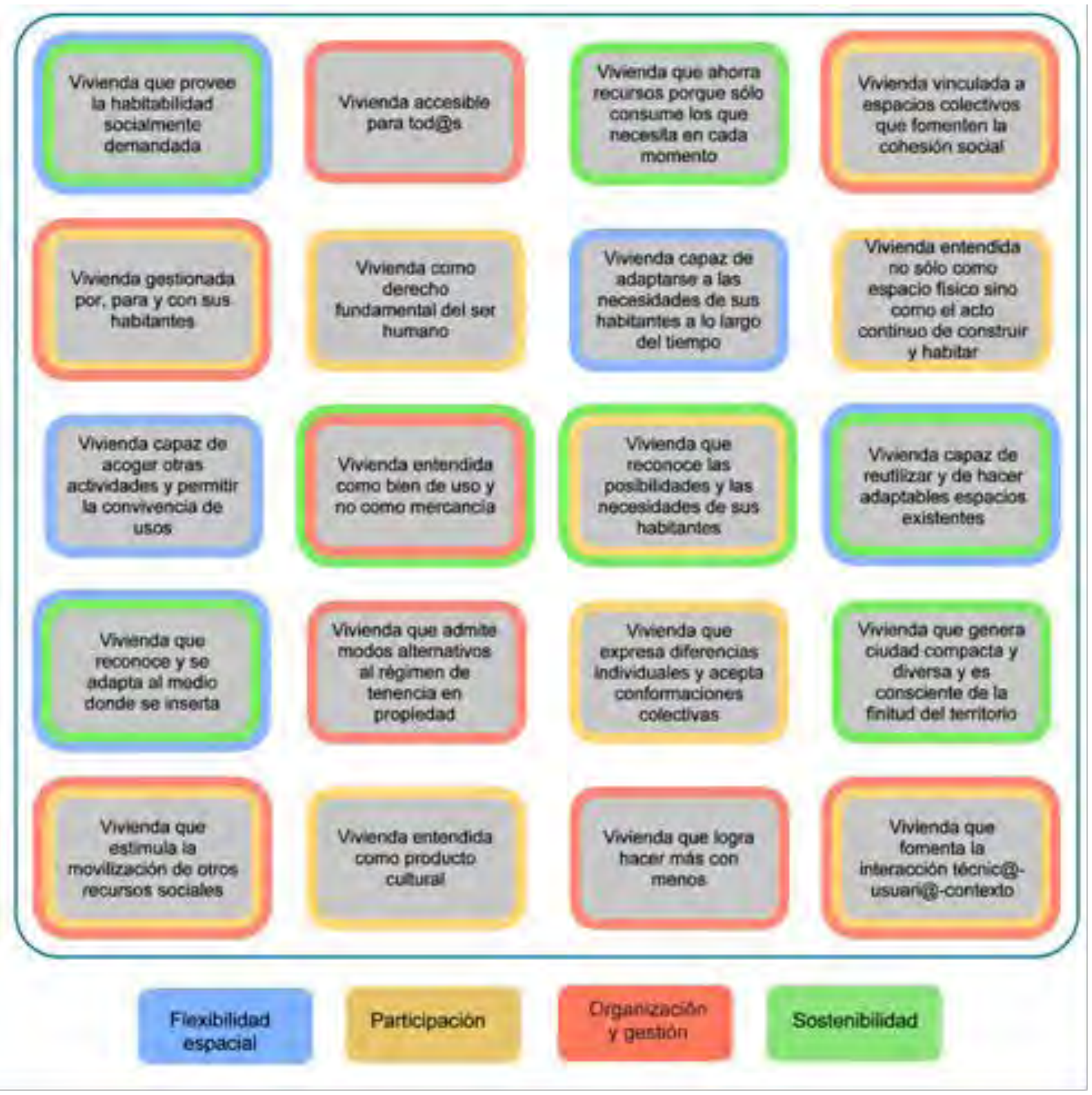

Figura 2. Características de "la vivienda como proceso". Fuente: Elaboración propia.

corresponde con considerar la vivienda como una mercancía y no como un derecho o un bien de uso, donde la vivienda es fundamentalmente un objeto en propiedad que se compra y se vende, es decir un objeto ligado a la inversión.

La vivienda se construye y termina en un momento determinado en el tiempo y posteriormente se usa en el estado en el que se ha terminado. Cualquier transformación posterior implica costo- sos procesos legales y constructivos, lo que limita la adaptación de la vivienda a las necesidades reales de las personas usuarias. Asimismo, la vivienda se entiende como un ente autosuficiente y como una unidad continua, dentro de la cual se incluyen todos los espacios y servicios necesarios, independientemente del perfil concreto de la utilización de estos espacios y servicios. Se trata de un objeto poco flexible, al no considerar las 
transformaciones naturales de las personas habitantes y, por tanto, las de sus espacios habitacionales, así como la evolución de estas transformaciones en el tiempo. Es un objeto que no se produce con la finalidad de satisfacer su función principal, la de proveer habitabilidad, porque está destinado a unas personas usuarias estereotipadas, singulares, neutrales, abstractas, masculinas y generalmente de clase media-alta. Es un objeto que, incrementado por su alta rigidez y desconexión de la realidad (porque responde a los imperativos del mercado), desaprovecha gran cantidad de recursos (naturales, económicos y sociales) y produce gran cantidad de residuos.

Por el contrario, considerar la vivienda como proceso permite dar respuesta a las necesidades y posibilidades de sus habitantes y, para ello, es imprescindible incorporar a las personas usuarias en el propio proceso. Desde esta óptica la vivienda, más que un objeto acabado, consistiría en una infraestructura básica conectada a espacios y servicios que va transformándose a lo largo del tiempo en función de las necesidades vitales y las posibilidades económicas de las personas usuarias.Esto implica que el proceso debe ser abierto, que recupere y actualice formas de participación y trabajo colaborativo entre todos los agentes implicados. Permite así hacer más con menos, aprovechando los recursos, porque se consiguen estimular las capacidades y recursos sociales, y porque ahorra recursos al utilizar sólo los realmente necesarios. La vivienda, así entendida, es capaz de satisfacer su función principal, la de proporcionar habitabilidad, siendo flexible y adaptándose a las demandas reales de la sociedad y a sus modos de vida, desde su pluralidad y desde sus necesidades cambiantes. En definitiva, considerar la vivienda como proceso implica entenderla como algo más que un espacio físico, como un acto que se desarrolla en el tiempo y no en un momento determinado, es decir, que entiende el acto de habitar.

\section{Antecedentes de la vivienda como proceso: la vivienda progresiva o semilla}

Las nociones de vivienda progresiva han sido exploradas y experimentadas en infinitud de alternativas por todo el mundo subdesarrollado (González Lobo, 1998). En el contexto latinoamericano según Enrique Ortiz, "responde a una práctica social, a la forma en que la mayor parte de la gente produce su vivienda, de acuerdo con la dinámica de sus recursos, posibilidades, necesidades y sueños" (Ortiz, 2007). Es una práctica que se adapta mejor a la realidad económica, a la dinámica de las familias pobres y a la necesidad de seguir invirtiendo en la consolidación de la vivienda. En definitiva se trata de ofrecer, partiendo de soluciones precarias en dimensiones, mayor calidad de vida a largo plazo y mayor flexibilidad para adaptarse a la dinámica familiar, posibilidades, necesidades y deseos, según Enrique Ortiz. Se integra pues dentro del concepto de "producción social de vivienda" muy extendido en América Latina.

En este sentido, Víctor Pelli nos habla de proceso, no referido tanto a la secuencia de construcción, sino a toda la concertación y gestión socioorganizativa que conduce a la resolución del problema habitacional. "En la medida que fuimos estableciendo contacto con la gente y entendiendo sus problemas, nos familiarizamos con la naturaleza real de las condiciones y de los recursos que concurren en la resolución de los problemas habitacionales”, comenta Pelli (1991). En este sentido define la vivienda como "conjunto de situaciones, bienes y servicios, desagregables en el tiempo y en el espacio, y en sus procesos de producción y de uso, es decir, que pueden ir 
construyéndose, concretándose, habilitándose y/o usándose a lo largo de etapas y circunstancias diferentes $y$, con frecuencia, intercambiables" (Pelli, 1992).

En este sentido Carlos González Lobo desarrolla un concepto de vivienda semilla o vivienda progresiva que denomina "gran galpón". Tipología de vivienda que desarrolla adquiriendo para ello mucho más volumen con posibilidad de ser habitado en el tiempo, por casi el mismo precio que el volumen de la vivienda en condiciones normales. Optando, de esta manera, por "soluciones de vivienda que partiendo de lotes de urbanización mínima y con "pies de casa" realizados con tecnologías apropiadas y apropiables y que consideren futuros crecimientos posibles, logran una habitabilidad desde el principio, y hasta el término del proceso edificatorio, una satisfacción espacial realista y en su circunstancia plena, ya que supone admitir desde el inicio, un futuro posible mejor, pese a las dificultades que esto entraña durante los esforzados años por venir en que culmine la tarea edificatoria" (González Lobo, 1998). En este sentido, en el prólogo del libro "Vivienda y Ciudad Posibles", Julián Salas nos habla del "gran galpón” de Carlos González Lobo como el que permite construir "partes de la ciudad posible", demostrando que partiendo de una "vivienda desnuda", construyendo de "poco a poco, la vestirán a su ritmo, a su gusto y en forma acorde con sus necesidades, algo que ocurre en el Conjunto Andalucía en Santiago de Chile" (ob. cit).

En la revista Vivienda Popular Julia Ferrero (1998) nos introduce el concepto de "vivienda evolutiva", como aquella que se produce dentro del proceso de desarrollo temporal que genera vivienda para los sectores de bajos recursos. "La vivienda es parte de un proceso de producción del hábitat", teniendo la potencialidad de desencadenar "un proceso de mejoramiento habitacional y social". La autora nos muestra cómo, si la vivienda evolutiva se identifica exclusivamente con la construcción de núcleos básicos y opera sólo como una respuesta al ajuste estructural, las consecuencias pueden ser negativas, ya que puede segregar a amplios sectores de la población, hacinamiento, poco confort ambiental o soluciones provisionales que no resuelven el problema básico del hábitat. Por este motivo, es necesario orientar la vivienda evolutiva tanto desde los aspectos físicos-espaciales, como socioorganizativos en la que se potencie la participación del usuario, con asesoramiento técnico de equipos interdisciplinares que entre todas las partes se incida a la construcción de ciudad. En definitiva, la vivienda crecedera surge como alternativa a la vivienda, ofreciendo estabilidad y enraizamiento de la familia en un lugar y en una comunidad humana con problemas y aspiraciones similares. Podemos decir, tal y como nos introduce Julia Ferrero, que "el hecho físico (casa) y el social (grupo) debe estar presente desde el principio de la acción para que se fortalezca y cada uno de sus componentes se desarrolle. Para ello, debe contar con apoyo externo técnico y financiero hasta lograr autonomía”.

En el contexto europeo, el concepto de vivienda como proceso se puede rastrear de la mano de dos autores, el inglés John Turner y el holandés John Habraken. Ambas posturas y propuestas surgen ante la problemática de la calidad de las propuestas estatales paternalistas en el alojamiento de los ciudadanos.

Turner (1997), que trabaja fundamentalmente en Sudamérica, defiende la capacidad de las poblaciones de autogestionar su vivienda, caracterizándola como un proceso que el estado simplemente debe apoyar. Las propuestas de Habraken (1975), intentan desarrollar metodologías para abrir los procesos industriales a los usuarios, y define un campo de reparto de responsabilidades en el proceso de definición del hábitat, para dar 
más participación a los ciudadanos. Ambos autores desde contextos y posicionamientos distintos plantean la necesidad de la participación de la ciudadanía en los aspectos fundamentales de la producción de su vivienda.

Estas ideas desarrolladas e implementadas en los años setenta se insertan en un momento en el que surgen varias líneas de trabajo y práctica social: el movimiento denominado "community architecture" en el Reino Unido, Los "community design centers" en Estados Unidos que apoyan y asesoran a poblaciones marginadas con problemas urbanos y todas las estrategias y planteamientos en Sudamérica de la "Producción social del Hábitat" (Pelli, Lungo, Romero y Bolivar, 1994).

En nuestro contexto estas ideas no llegaron a consolidar una corriente definida de práctica. Figuras como la de Ramón Moliner (1976) y otros generaron debates y propuestas en los años setenta. Profesionales como Pedro Lorenzo (2005) han desarrollado y aplicado estos planteamientos principalmente en el ámbito de la cooperación internacional.

\section{La vivienda como proceso}

El concepto de vivienda como proceso quiere abordarse desde una visión sistémica e integrada de la realidad, concibiendo el desarrollo de la misma como un proceso inacabado y perfectible en el tiempo. Por este motivo es necesario incorporar toda la complejidad de los distintos aspectos que la componen, integrando las partes con el todo y el todo con las partes (Morin, 2007). Se concibe la vivienda, por lo tanto, como un ecosistema sostenible donde interaccionan la flexibilidad espacial, la participación y la organización y gestión de la ciudadanía. Tres ingredientes que se retroalimentan, pero que a su vez tienen su propia idiosincrasia y conforman entre todos un único concepto, "la vivienda como proceso". Esta visión integral y holística de la vivienda permite a través de estas interrelaciones, una mejora en la accesibilidad, habitabilidad y bienestar social de la ciudadanía en los espacios que habita con proyección en el tiempo.

\section{Flexibilidad Sostenibilidad espacial}

Accesibilidad

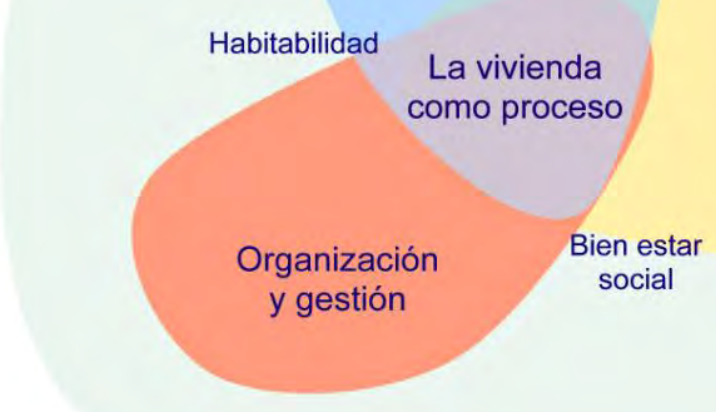

Figura 3: Visión integral de la vivienda. Fuente: Elaboración propia. 
Estos tres niveles, el nivel espacial/tipológico, el nivel social/participativo y el nivel relacionado con la gestión de los procesos, son interdependientes y sinérgicos, y por lo tanto no deben tomarse por separado; exigen una consideración en su conjunto, ya que se influyen y condicionan unos a otros; y pueden alcanzar mayor o menor efectividad en la medida que interactúen entre sí. Por ejemplo, una participación activa y real en los procesos requiere una gestión adecuada que la garantice; de la misma forma que proveer flexibilidad "física" a un espacio no es suficiente para asegurar que se dé la flexibilidad, para ello son necesarios también mecanismos de participación y gestión adecuados. En el presente artículo desarrollamos el concepto de vivienda como proceso, abordándolo desde su aspecto físico. Esto no significa que podamos obviar la componente social dentro del mismo, pero se ha querido centrar en las posibilidades que puede ofrecernos las transformaciones espaciales en su capacidad de adaptación a las diferentes necesidades sociales existentes y posibles. Por ello aquí nos centramos en el estudio de las estrategias que proporcionan flexibilidad. Flexibilidad en la vivienda, como la característica que le permite adaptarse a lo largo de su ciclo de vida a los cambios de las necesidades y los requerimientos de las personas usuarias y de su entorno. Esto es, desde estrategias que ofrecen variedad tipológica o diseño participativo, hasta estrategias que ofrecen adaptabilidad a través de cambios en el uso o la función de los espacios o a través de la concepción técnica y constructiva.

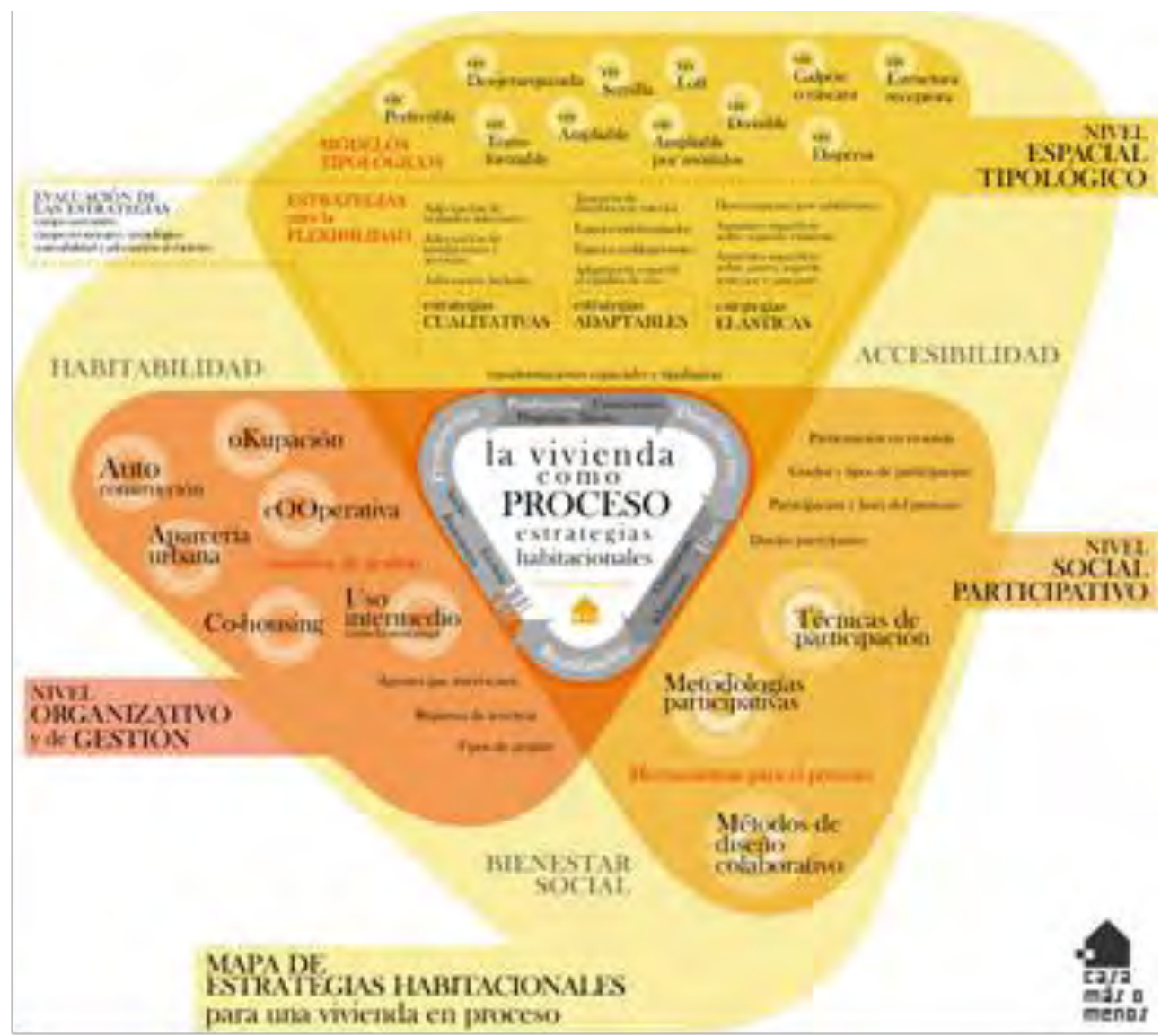

Figura 4. Mapa de Estrategias Habitacionales.Fuente: Elaboración propia. 


\section{Estrategias de proporción de flexibilidad}

La flexibilidad en la vivienda puede considerarse como una característica que le permite adaptarse a lo largo de su ciclo de vida a los cambios de las necesidades y los requerimientos de las personas usuarias y de su entorno. Existen multitud de definiciones y acepciones del concepto de flexibilidad en el ámbito de la vivienda, que engloban a su vez diferentes tipos de categorías o aspectos.

Realizando un breve repaso de algunos teóricos que reflexionan sobre este tema puede darse un ejemplo ello.

El equipo formado por Gibb Alistair, Robert Schmidt, Toru Eguchi and Simon Austin (Schmidt, 2010) considera que "la adaptabilidad es una característica de diseño que engloba estrategias espaciales, estructurales y de servicios, la cual permite al artefacto físico un grado de maleabilidad en respuesta a los parámetros operacionales que cambian a lo largo del tiempo. Este cambio estratégico muestra a los edificios no como obras acabadas fuera del tiempo, sino como objetos imperfectos cuyas formas están en continuo movimiento evolucionando para adaptarse a las metamorfosis funcionales, tecnológicas y estéticas de la sociedad." El propósito de este equipo es definir y clasificar las estrategias que representan la capacidad física de los edificios para ser adaptables, las cuales pueden englobarse en seis categorías finales: ajustable, versátil, reacondicionable, convertible, escalable y móvil.

Jeremy Till y Tatjana Schneider (Schneider, 2005a, 2005b) definen la vivienda flexible como la vivienda que puede adaptarse a las necesidades cambiantes de los usuarios. Consideran que la categoría flexible en su definición es más amplia que lo que pueda significar vivienda adaptable y que el grado de flexibilidad está determinado de dos maneras: en primer lugar, por la posibilidad de adaptabilidad embebida en la construcción definida como "capaz de diferentes usos sociales" $y$ en segundo lugar por la posibilidad de flexibili- dad, definida como "capaz de diferentes configuraciones físicas". En cuanto a los métodos con los cuales la flexibilidad ha sido o puede ser conseguida, Till y Schneider, plantean clasificarlos en dos categorías amplias que son uso y tecnología. Con uso se refieren a la forma en que el diseño afecta a la forma de ocupar la vivienda a lo largo del tiempo, y generalmente se refiere a la flexibilidad que proporciona la distribución de la vivienda. Tecnología tiene que ver con temas de construcción y servicios, y con la forma en la que esto afecta a la posibilidad de flexibilidad. A su vez, subdividen cada una de estas dos categorías en las que usan técnicas soft y técnicas hard. Soft se refiere a tácticas que permiten cierta indeterminación, mientras que hard se refiere a elementos que determinan más específicamente la forma en que el diseño debe ser usado.

Bernard Leupen (Leupen, 2006), antes de plantear su clasificación de los tipos de mutabilidad o alterabilidad (changeability), como él la denomina, realiza también un repaso de los tipos de clasificaciones propuestas por otros autores. Como consecuencia de este estudio, Leupen destila tres definiciones para su investigación: alterabilidad (alterability), extensibilidad (extendability) y polivalencia (polyvalence). Define alterabilidad como alteraciones internas, que pueden consistir en, desde cambiar la posición de una puerta, pasando por eliminar un tabique, hasta cambiar la distribución completa de la vivienda. Define extensibilidad como modificación de la superficie de una vivienda, lo cual puede darse sin consecuencias para las viviendas de alrededor (extensibilidad independiente) o con consecuencias para las viviendas de alrededor (extensibilidad dependiente). Por último, polivalencia engloba todas las formas de adaptabilidad a través del uso, es decir, la define como el uso múltiple de los espacios sin que haya una modificación arquitectónica o estructural, o incluyendo como mucho, un cambio en la distribución interna usando tabiques móviles y puertas correderas. 
Ignacio Paricio (2000), considera la flexibilidad como la respuesta a la diversidad de los modos de los programas de ocupación y de las formas de vida. Paricio plantea otros medios para conseguir la flexibilidad:

- Por medio de una compartimentación ambigua que admita una polivalencia de uso de los espacios sin necesidad de transformarlos.

- Reduciendo los elementos de división o incorporando cerramientos móviles.

- Por la posibilidad de incorporar nuevos espacios a la vivienda.

- Por una concepción de la vivienda que distinga entre componentes estructurales e infraestructurales, de carácter básico y fijo, y componentes de compartimentación, de equipos y acabados, incorporables y modificables según los deseos de los ocupantes a lo largo del tiempo.

Jia Beisi (Beisi, 1995) hace dos reflexiones que nos parecen interesantes de señalar sobre la adaptabilidad. La primera es que la adaptabilidad es posibilidad de uso. Con esto quiere decir que la posibilidad de adaptabilidad física y la posibilidad de usar esa adaptabilidad, son dos cosas distintas. La adaptabilidad no es sólo un factor físico, sino también una cuestión de conocimiento y gestión. En segundo lugar, la adaptabilidad es un proceso. El concepto de adaptabilidad debe aparecer desde la fase de programación y se puede aplicar en las fases de diseño y proyecto, construcción, uso y rehabilitación. Beisi estudia seis aspectos: la posibilidad de intercambio de habitaciones (entre viviendas colindantes), la posibilidad de variar el número total de viviendas (dentro de la estructura global del edificio), la posibilidad de espacios multifuncionales, la posibilidad de cambios en las conexiones entre espacios, la posibilidad de cambios en la cantidad y el tamaño de los espacios y la posibilidad de cambios en los accesorios (accessories).

\section{Clasificación propuesta de estrategias de proporción de flexibilidad}

A continuación, se propone una identificación y clasificación de estrategias cuyo objetivo es la proporción de flexibilidad en el ámbito de la vivienda. La clasificación propuesta atiende principalmente al tipo de flexibilidad proporcionada por cada una de ellas, estando en relación directa, a su vez, con el tipo de necesidades del usuario que satisfacen o con los tipos de cambios que atienden:

- Estrategias cualitativas. Introducen un cambio en la cualidad de la vivienda respondiendo a la necesidad del usuario de personalizar o adecuar técnicamente su vivienda.

- Estrategias adaptables. Son estrategias que permiten un cambio de función de los espacios, respondiendo a la necesidad del usuario de una adecuación funcional de la vivienda.

- Estrategias elásticas. Introducen un cambio en el tamaño de la vivienda para responder también a la necesidad de una adecuación funcional de la vivienda.

Estrategias aplic ables tanto en viviendas aisladas como en agrupaciones de viviendas.

Estrategias funcionales Estrategias formales
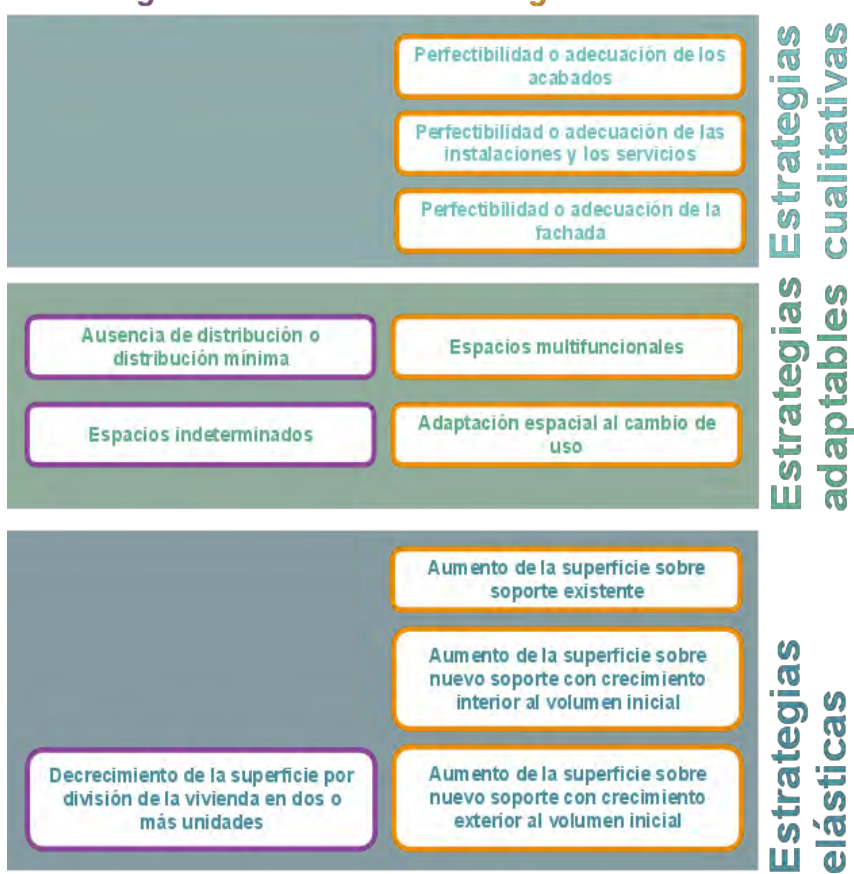

Figura 5. Estrategias aplicables en viviendas aisladas y en viviendas colectivas. Fuente: Elaboración propia. 


\section{Estrategias Cualitativas}

Las estrategias cualitativas son estrategias que introducen cambios en las propiedades y calidades de los elementos de la vivienda, posibilitando que éstos cambien, mejoren, se recoloquen, aumenten o incluso desaparezcan. El sentido de las estrategias cualitativas engloba tanto el concepto de perfectibilidad como el de adecuación.

La perfectibilidad está asociada a la posibilidad de mejora. Aplicar una estrategia basada en la perfectibilidad significaría dotar a la vivienda de los elementos básicos para proporcionar la habitabilidad mínima necesaria permitiendo mejoras a lo largo del tiempo. Ignacio Paricio (2000) define la perfectibilidad como "la reducción de la vivienda a sus elementos esenciales para una primera ocupación, de manera que esté prevista su mejora o ampliación posterior".

Tener en cuenta la perfectibilidad de los elementos de una vivienda en su diseño conlleva generalmente una reducción de los costes de construcción, puesto que se utilizan materiales básicos y se dota a la vivienda de lo mínimo necesario. Esto constituye un ahorro directo de materiales y recursos, lo cual se traduce en un menor impacto sobre el medio ambiente, y, dependiendo del tipo de gestión y de la producción de la vivienda, puede traducirse también en un menor coste para el usuario.

La producción de vivienda ha tendido en los últimos años a elevar el nivel de calidad y de equipamiento inicial de las viviendas, respecto a décadas anteriores. Esto dificulta el acceso a la vivienda de los usuarios que no precisen de ese nivel de calidad en una primera ocupación o que no dispongan de los medios económicos suficientes.

Por otro lado una mayor determinación de los elementos de la vivienda, si no han sido consultados previamente con el usuario, llevan inevitablemente a una mayor inadecuación a sus gustos y necesidades, por lo que es práctica habitual que en la primera ocupación se invierta en la sustitución de materiales y equipamientos que ni siquiera han llegado a ser utilizados, con el consiguiente gasto económico y de recursos.

Por otro lado, la adecuación está asociada a la posibilidad de adaptación o reacondicionamiento de elementos existentes a una nueva tarea o función. Aunque la adecuación es un concepto muy cercano al de perfectibilidad, lo queremos diferenciar porque está más relacionado con el cambio de la función de los elementos, lo cual no debe significar necesariamente una mejora (intrínseca sin embargo al concepto de perfectibilidad), aunque dicha mejora suela estar muchas veces implícita en el cambio.

La posibilidad de adecuación es más usual cuando la vivienda ya ha sido habitada durante un periodo de tiempo y es necesario, por ejemplo, el cambio de algunos elementos por obsolescencia o la adecuación a las necesidades de un nuevo usuario.

Se proponen una serie de estrategias cualitativas:

\section{Perfectibilidad o adecuación de los acabados interiores}

La perfectibilidad o adecuación de los acabados interiores suele estar ligada sobre todo a la necesidad de personalizar la vivienda, es decir, a una adecuación estética, o también, a una adecuación económica (construcción de la vivienda con acabados básicos para la primera ocupación y mejora progresiva de la calidad a lo largo de su vida).

\section{Perfectibilidad o adecuación de la fachada}

La fachada de un edificio suele tener que ser rehabilitada (reparación, sustitución o incorporación de algún elemento) cada veinte años por consideraciones técnicas o estéticas. La perfectibilidad o adecuación de la fachada puede, por un lado, estar relacionada con una adecuación estética, entendida no sólo como la posibilidad de 
cambiar el aspecto exterior de la fachada (en la medida que esté permitido), así como la posibilidad de su reparación en caso de deterioro. Por otro lado, está relacionada con la necesidad de mejorar el comportamiento energético de la vivienda, en el cual la fachada juega un papel fundamental por ser parte de la envolvente térmica.

\section{Estrategias adaptables}

Las estrategias adaptables son estrategias que permiten un cambio de función de los espacios. En este tipo de estrategias cabe distinguir entre lo versátil o capacidad del espacio de cambiar de uso sin transformarse físicamente, y lo convertible o capacidad del espacio de diferentes configuraciones físicas a través de transformaciones que alteren su distribución interna.

Las estrategias adaptables satisfacen la necesidad del usuario de una adecuación funcional de la vivienda sin necesidad de una modificación del tamaño de la misma.

Se proponen una serie de estrategias adaptables:

\section{Espacios indeterminados}

Esta estrategia se basa en dotar a la vivienda de espacios indeterminados, que pueden cambiar de uso sin transformarse físicamente. Los espacios se desjerarquizan para ser capaces de albergar cualquier función, prevista inicialmente o no.

\section{Ausencia de distribución interior}

Esta estrategia consiste en dotar a la vivienda del máximo espacio posible para que sea usado de la forma que el usuario quiera, es decir, prescindir de la distribución interior que divide a la vivienda en distintos espacios o tratar de reducirla al mínimo necesario. Se trata de crear un gran volumen espacial que genera un espacio ambiguo, indefinido y apropiable por cada usuario de manera creativa.

\section{Espacios multifuncionales}

La multifuncionalidad de un espacio significa que dicho espacio puede ser usado para distintos usos. A diferencia de los espacios indeterminados, los espacios multifuncionales se diseñan para una cantidad limitada de usos previstos y predeterminados. La multifuncionalidad implica que desde el diseño se determina cómo van a ser usados los espacios, es decir, la adaptabilidad proporcionada por espacios multifuncionales está muy condicionada por el diseño previo y deja poco margen de actuación al usuario. Es una estrategia que está ligada a situaciones en las que el espacio es escaso y se quiere aprovechar al máximo.

\section{Transformación espacial al cambio de uso}

La adaptación espacial al cambio de uso implica una transformación física del espacio para facilitar que sea usado para distintas funciones no predeterminadas. Los espacios son convertibles (se transforman físicamente para adaptarse al nuevo uso) y para ello suelen usarse divisiones interiores móviles o de fácil reubicación, puertas correderas, muebles móviles o transformables, de manera que se puedan conseguir distintas configuraciones de la distribución interior de la vivienda. Depende de cómo sea diseñada esta estrategia puede ser más o menos determinante en cuanto al modo de usar la vivienda posteriormente.

\section{Estrategias Elásticas}

Las estrategias elásticas son estrategias que permiten, como las adaptables, un cambio de función de los espacios, pero en este caso se consigue escalando las viviendas, haciendo que aumenten o disminuyan de tamaño.

La vivienda parte de un estado adecuado a las necesidades iniciales del usuario y va aumentando de tamaño a medida que se va necesitando más espacio y/o van aumentando las posibilidades económicas. También puede llegar un momento en el que, por el contrario, no sea necesario todo el espacio disponible y se pueda prescin- 
dir de parte del mismo.

Se proponen una serie de estrategias elásticas:

\section{Decrecimiento de la superficie por división de la vivienda en dos o más unidades}

Esta estrategia se plantea como posible forma de decrecimiento de la vivienda después de un período de tiempo de su vida útil, en un momento en el que ya no es necesaria para el usuario toda la superficie de la misma, de forma que la vivienda original se divida en dos o más unidades, o ceda parte de su superficie a otra vivienda. Se considera como una estrategia funcional principalmente puesto que aunque requiere una intervención constructiva para la división física de la vivienda, ésta no debe ser de gran complejidad técnica si la planificación ha sido adecuada. Si por el contrario, si la división no hubiera sido planificada, ésta puede resultar compleja y cara.

\section{Aumento de la superficie de la vivienda sobre soporte existente}

Esta estrategia permite el crecimiento de la superficie útil de la vivienda. Su característica fundamental es que la vivienda se apropia de espacios que ya estaban construidos y pertenecían a ella (soporte existente) pero no se consideraban habitables o no contaban como superficie útil (no alcanzan una altura mínima, no son accesibles, están abiertos...). La intervención necesaria a nivel constructivo por consiguiente es de pequeña o mediana envergadura (cerrar una fachada, abrir una ventana,...), es decir, que no es necesario modificar ni ampliar la estructura. Los nuevos espacios pueden crecer interior o exteriormente al volumen inicial de la vivienda. Un ejemplo del tipo de espacios que se añaden podría ser terrazas y balcones que se cierran para formar parte de los espacios adyacentes, trasteros o buhardillas que se convierten en habitaciones, altillos que se convierten camas altas, etc.

\section{Aumento de la superficie de la vivienda sobre nuevo soporte con crecimiento interior al volumen inicial}

Esta estrategia permite el crecimiento de la superficie útil de la vivienda, siendo éste un crecimiento interior al volumen inicial de la vivienda. La creación de nueva superficie útil se consigue con la construcción de niveles intermedios o entreplantas (nuevo soporte). El estado inicial de la vivienda consiste en un volumen máximo que es capaz de albergar los crecimientos posteriores. El volumen inicial es un espacio acotado, y aunque no está habitado en su manera óptima, es un espacio útil y habitable con potencial de "inpansión" (expansión hacia dentro). El crecimiento de la vivienda, al ser interior al volumen inicial, no altera la relación de la vivienda con el espacio adyacente. Por otro lado, la envolvente del edificio no se ve alterada sustancialmente, aunque puede modificarse introduciendo nuevos huecos (en el caso de que no existieran) para proporcionar luz y ventilación a los nuevos espacios creados.

\section{Aumento de la superficie de la vivienda sobre nuevo soporte con crecimiento exterior al volumen inicial}

Esta estrategia permite el crecimiento de la superficie útil de la vivienda. Los espacios se crean sobre un nuevo soporte exterior al volumen inicial de la vivienda, necesitando para ello la construcción de elementos estructurales tales como forjados, pilares, cimentación, etc... Los nuevos espacios creados pueden ser anexos o no a la vivienda. La ampliación de la vivienda puede consistir en la construcción de una nueva planta en altura, colmatar un patio, añadir un espacio en voladizo, etc.

\section{Estrategias de flexibilidad aplicables en viviendas colectivas}

La vivienda entendida como ente aislado del contexto y de la comunidad donde se ubica no es un modelo que pueda ser sustentable en el futuro. 
Es necesario que nuestras ciudades apuesten por ser compactas y conformadas por viviendas colectivas integradas en el entramado urbano y social donde habita. En este sentido, desde el punto de vista de la flexibilidad, la vivienda colectiva abre nuevas posibilidades, al considerar que transciende a la unidad habitacional y se extiende hacia los espacios intermedios entre las viviendas, y entre ellas y el entorno urbano; que existen determinados servicios que pueden satisfacerse fuera de la vivienda de forma comunitaria; o que pueden producirse intercambios de viviendas o de espacios dentro del mismo edificio.

La vivienda colectiva a la que nos referimos, es aquélla que además de ser una agrupación física de viviendas en una estructura o edificio común, comporta la formación de una comunidad de vecinos al existir espacios o elementos comunes en copropiedad.

La existencia y características de los elementos comunes pueden variar desde el mínimo indispensable para proveer el acceso de las personas y servicios a las viviendas, hasta una amplia gama de espacios intermedios que favorezcan la socialización. Estos espacios intermedios entre lo privado y lo público son fundamentalmente lugares de transición entre la casa y la calle, entre lo particular y lo colectivo, entre el "dentro" y el "fuera"; son por lo tanto lugares de relación y de proximidad. Los espacios intermedios que se proponen pueden clasificarse en función de su uso y su grado de privacidad/colectividad:

- Límites intermedios. Espacios que ponen en relación el interior y el exterior situados en la franja perimetral de las viviendas. Se trata de espacios-umbrales, espacios de indefinición que otorgan porosidad a los límites.

- Zonas comunes. Espacios que se comparten entre vecinos y vecinas como los descansillos, corredores de acceso, zaguanes, núcleos de comunicación vertical y horizontal.
Las dimensiones y diseño de estos espacios pueden propiciar que sean lugares de encuentro, lugares seguros, lugares accesibles.

- Espacios compartidos. Espacios que posibilitan y potencian la vida en comunidad. Espacios que pertenecen a la comunidad con posibilidad de uso por la totalidad de la comunidad en cada momento como cocinas comunes, lavandería, tendedero, comedores, cuarto de plancha, jardín, huerto comunitario...

- Espacios de uso comunitario. Espacios pertenecientes y gestionados por la comunidad con posibilidad de uso privativo por parte de los integrantes de la comunidad, pero que no necesariamente tienen que ser espacios de uso compartido. Permiten añadir a la agrupación otros usos y funciones. Son espacios usados por las personas que lo necesiten en ese momento, pudiéndose establecer distintos modos de adjudicación (rotación, lista de espera,...) Estos espacios pueden ser lugares de trabajo, viviendas/espacios disponibles, tienda, almacén,....

- Espacios para la convivencia de usos con el barrio. Espacios dentro de la agrupación con usos compartidos a escala de barrio, como una ludoteca, oficinas, biblioteca, tiendas...

- Espacio público. Muchas veces la agrupación de viviendas está directamente relacionada con el espacio público (calle, plaza, parque,...) constituyendo éste su espacio de relación y convivencia.

\section{Modelos tipológicos}

A partir de aquí, se presentan una serie de modelos tipológicos de viviendas en proceso que constituyen los casos más representativos de las distintas configuraciones de viviendas flexibles de la unidad de vivienda. Estos modelos tipológicos han sido seleccionados de muy diferentes contextos. Algunos son modelos bastante experimenta- 
dos en la vivienda informal, otros de experiencias venidas del norte de Europa. El sentido de haberlos seleccionado no significa necesariamente que deban llevarse a la práctica de forma idéntica, en planta baja y en ciudad de baja densidad. Se toman de cara a aprender de la práctica de hacer viviendas con bajos recursos, que se van construyendo poco a poco, y que podrían ser adaptadas para ser introducidas en la ciudad formal y compacta. Otros modelos tipológicos que se han rescatado, parten de realidades bastante experimentadas en la ciudad formal, y que consideramos relevantes por sus posibilidades de transformación con el uso del mismo en el tiempo.

\section{Vivienda Perfectible}

Vivienda que está preparada de antemano para ser mejorada y completada en el tiempo. Vivienda que permite mejoras de carácter cualitativo, incorporando acabados, instalaciones, aumentando confort y calidad en la vivienda.

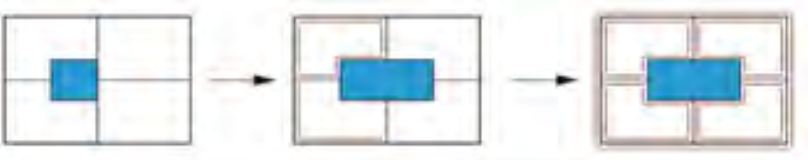

Figura 6. Esquema de la vivienda perfectible. Fuente: Elaboración propia.

\section{Vivienda Loft.}

Vivienda con gran espacio único distribuido $\mathrm{y}$ compartimentado con mobiliario interior. Espacio ambiguo, indefinido y apropiable por cada usuario de manera versátil. Sin tabiquería interior, sino con mobiliario móvil con capacidad de transformación en función de las necesidades del momento.
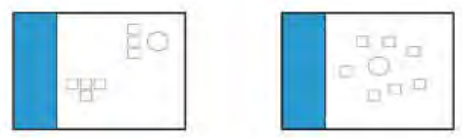

Figura 7. Esquema de la vivienda loft. Fuente: Elaboración propia.

\section{Vivienda Desjerarquizada.}

Vivienda con espacios sin uso definido y estancias que tienen más o menos las mismas cualidades. Compuesto por espacios con características similares en cuanto a geometría, dimensiones y relación con el exterior que permiten ser utilizados de manera indistinta y cambiante en el tiempo.

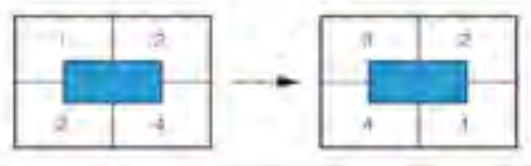

Figura 8. Esquema de la vivienda desjerarquizada. Fuente: Elaboración propia.

\section{Vivienda Transformable.}

Vivienda que puede transformar sus espacios gracias a tabiquerías que tienen previsto posibilidades de cambio con operaciones sencillas, para dotar el espacio de cualidades distintas, ya sean visuales, espaciales o funcionales. Estos elementos pueden ser tabiques móviles, puertas correderas o paneles de fácil reubicación.

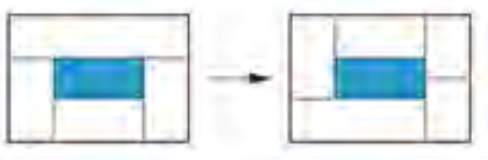

Figura 9. Esquema de la vivienda transformable. Fuente: Elaboración propia.

\section{Vivienda Estructura Receptora.}

Vivienda que se conforma a partir de una estructura base, formada por elementos inamovibles propuestos por el técnico y sobre los cuales el usuario no tiene control individual. Sobre ella se incorporan unas unidades separables, componentes adaptables sobre las cuales el usuario tiene control individual.
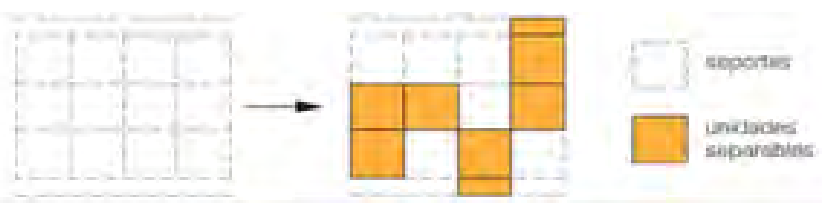

Figura 10. Esquema de la vivienda estructura receptora. Fuente: Elaboración propia. 


\section{Vivienda Ampliable.}

Vivienda que se extiende ocupando metros cuadrados disponibles o añadidos que no forman parte de su superficie útil inicial. Los nuevos espacios pueden crecer hacia el interior o exterior del volumen inicial de la vivienda. Un ejemplo del tipo de espacios que se añaden podrían ser terrazas, balcones, trasteros, altillos, buhardillas, etc.

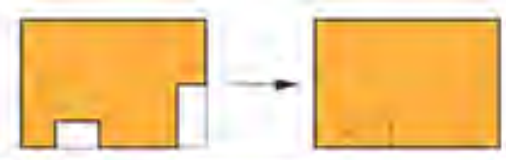

Figura 11. Esquema de la vivienda ampliable. Fuente: Elaboración propia.

\section{Vivienda Ampliable por Módulos.}

Vivienda que puede agregar o ceder módulos ampliando o disminuyendo su superficie útil. La agregación puede estar prevista desde el diseño del proyecto o incorporarse durante la vida útil de la vivienda.
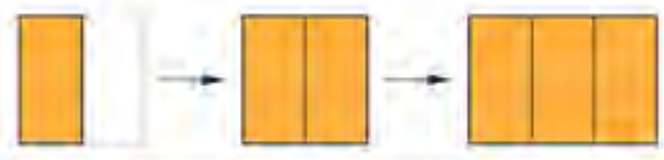

Figura 12. Esquema de la vivienda ampliable por módulos. Fuente: Elaboración propia.

\section{Vivienda Galpón o Cáscara.}

La vivienda Galpón es una vivienda con un volumen mayor al que se ocupa en un primer momento, permitiendo así realizar crecimientos interiores a posteriori, construyendo entreplantas para ello, sin alterar el volumen inicial.

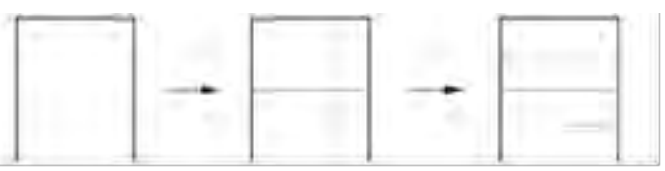

Figura 13. Esquema de la vivienda galpón o cáscara. Fuente: Elaboración propia.

\section{Vivienda Semilla.}

La vivienda semilla se conforma a partir de un cuarto o un habitáculo básico habitable, planteado como el germen de una vivienda plena que crecerá con el tiempo según el ritmo biológico y las posibilidades de los usuarios.

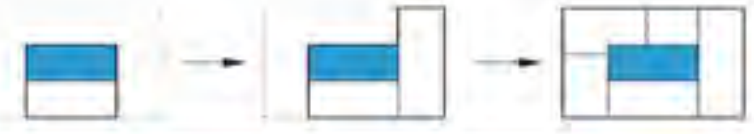

Figura 14. Esquema de la vivienda semilla. Fuente: Elaboración propia.

\section{Vivienda Dispersa.}

Vivienda que puede aumentar su superficie útil con espacios separados de la unidad principal. spacios habitables distribuidos por el edificio o or el conjunto del edificio de viviendas.

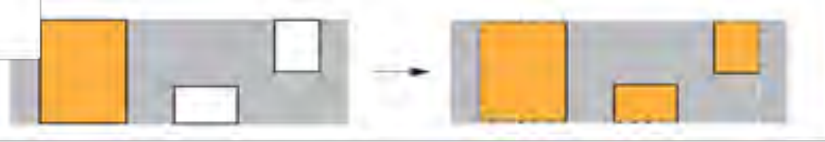

Figura 15. Esquema de la vivienda dispersa. Fuente: Elaboración propia.

\section{Vivienda Divisible.}

Vivienda que puede dividirse en dos o varias viviendas durante su vida útil, previendo acceso alternativo para ello. También puede tratarse de una vivienda que cede espacio a otras viviendas, a otros usos o al espacio comunitario del edificio.

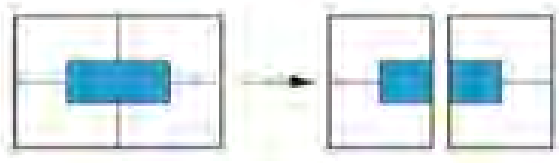

Figura 16. Esquema de la vivienda divisible. Fuente: Elaboración propia.

\section{Experiencias de viviendas colectivas entendidas como proceso}

Existen multitud de experiencias realizadas en diferentes contextos a lo largo del mundo que llevan a cabo y ponen en valor la experiencia colectiva de lo doméstico. Por ello, si queremos replantearnos los procesos de generación de vivienda, es necesario conocerlos y visibilizarlos para aprender de sus aciertos así como de sus errores. Las estrategias de proporción de flexibilidad y los modelos tipológicos anteriormente expuestos, han tomado como referentes estas experiencias previas, programas, metodologías y formas de hacer recopiladas.

Creemos importante realizar una labor de traduc- 
ción y reinterpretación para su puesta en práctica en el contexto que nos rodea, en una coyuntura económica y política en la que es importante repensar la ciudad para proponer otras formas de hacer. Se trata, en la mayoría de los casos, no tanto de inventar como de redescubrir y retomar caminos olvidados, que conocen la escasez como forma de vida, y otras épocas donde lo social ha estado más presente, con el fin de incorporar a la vivienda los condicionantes económicos, sociales y medioambientales del momento actual.

Es importante señalar que en un proceso colectivo de vivienda no hay recetas que se puedan importar directamente, que cada realidad, comunidad, y coyuntura es diferente. Será el trabajo colaborativo entre técnicos y personas usuarias, el que determinará la toma de decisiones a lo largo del proceso. Por lo tanto, no se pretende tanto ofrecer una hoja de ruta que garantice el buen hacer, sino ofrecer herramientas y claves posibles para que los modelos de vivienda tengan capacidad de adaptación a las necesidades actuales y cambiantes de la ciudadanía. En este sentido, a continuación se muestra una parte de la selección de experiencias que, cada una en su medida, desde diferentes perspectivas y contextos han intentado llevar a cabo viviendas colectivas entendidas como "procesos".

\section{Ökohaus. Frei Otto, Hermann Kandel. Berlin, Alemania. 1980-1992}

\section{Vivienda transformable, vivienda} ampliable, vivienda dispersa, vivienda estructura receptora, vivienda divisible

¿Por qué las personas sólo pueden habitar su propia casa, conformada según sus deseos, en las viviendas unifamiliares aisladas, y no en las viviendas colectivas en altura? La preocupación de Frei Otto en este aspecto le llevó a diseñar en 1951 una estructura de muchas plantas en la que cabían viviendas unifamiliares, cada una distinta a las demás, adaptándose a distintos habitantes. En 1980 tuvo la oportunidad de desarrollar su idea gracias al IBA de Berlín. Doce años más tarde, habiendo cambiado su ubicación, nació el proyecto experimental de la eco-casa. Las dieciocho familias participaron en el diseño junto con los arquitectos, e incluso en algunos de estos casos, colaboraron en la construcción de propias viviendas.

Los arquitectos responsables del proyecto trabajaron junto a un equipo multidisciplinar. No dieron ninguna indicación formal a los vecinos, sólo intervinieron para resolver discrepancias. Los edificios fueron concebidos como estanterías jardín abiertas al exterior. Los propietarios adquirieron por 75 años los derechos de superficie de las parcelas en planta para diseñar sus dúplex. Se ha previsto tabiquerías desmontabas para futuros cambios, espacios de reserva para posibles crecimientos de las viviendas sean o no contiguos y espacios exteriores de apropiación reversible. Igualmente se ha previsto la utilización de divisiones, carpinterías desmontables y tabiques móviles. Tanto el sistema estructural, como la distribución de huecos en fachada y la distribución de las instalaciones permiten cambios en la organización de los espacios. La tipología admite futuras agrupaciones o segregaciones.

El edificio se rige sobre tres estructuras básicas de columnas y placas de hormigón armado, donde se disponen las viviendas y jardines adicionales en las divisiones horizontales. Los edificios se adecuaron al lugar, preservando toda la vegetación original sin necesidad de talar ningún árbol. Sólo se permite el paso a los peatones sobre un paso elevado del suelo dejando fluir la vegetación y los animales. La agrupación dispone de espacios comunitarios de uso compartido, espacios intermedios como balcones y terrazas y una parte de la cubierta para uso comunitario. 


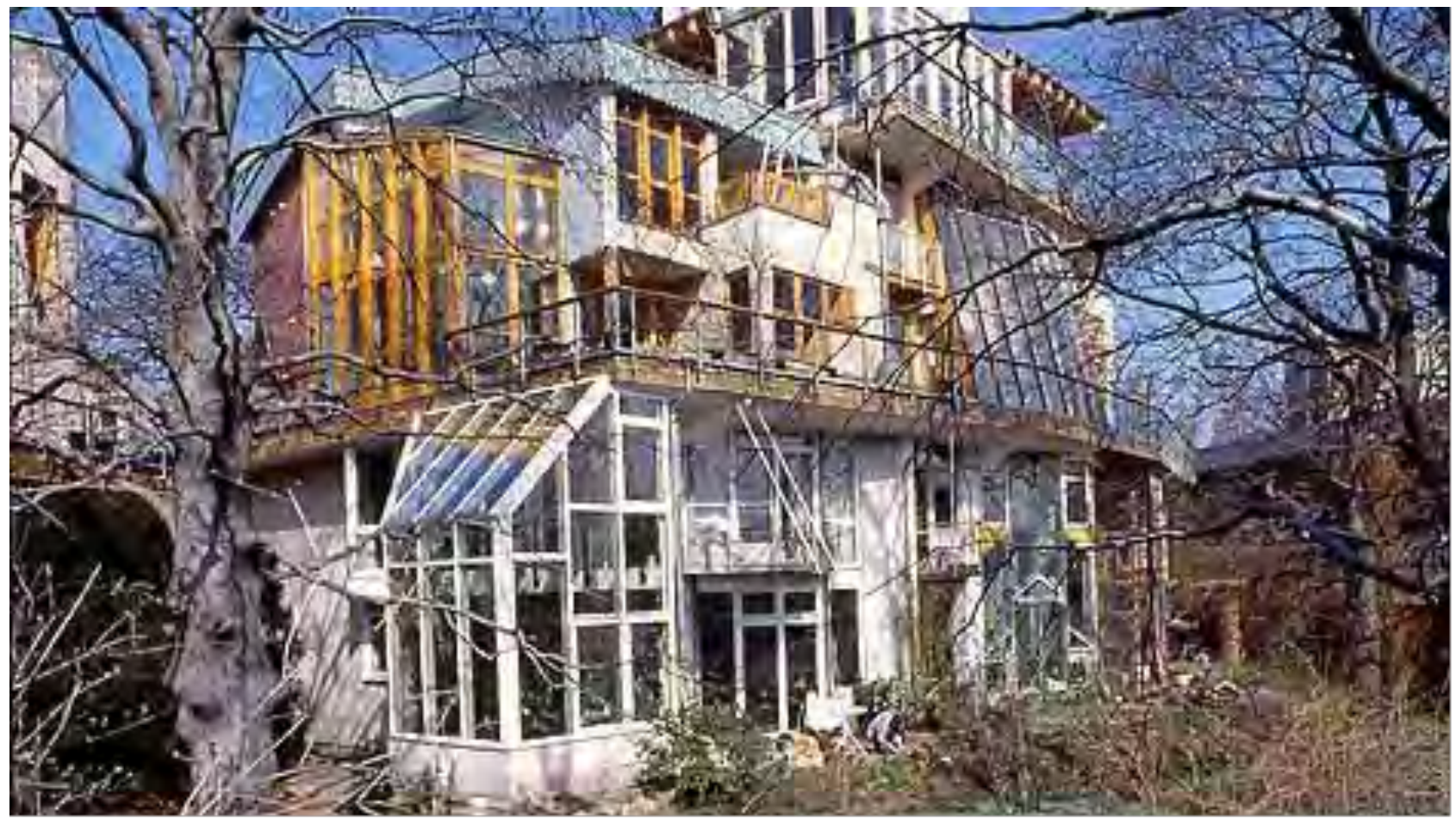

Figura 17. Ókohaus. Berlin. Frei Otto. Fuente: <http://www.solidararchitekten.de/projekte/baugemeinschaft/solidar-oekohaus-berlin.html>.

\section{Cooperativa Guerrero. Centro Operacional de Vivienda y Poblamiento AC. Ciudad de México. 1975-1978}

\section{Vivienda estructura receptora, Vivienda galpón o cáscara}

Cooperativa Guerrero es un proyecto de sustitución de vivienda que se desarrolla en el centro de Ciudad de México en un terreno de una extensión de $1450 \mathrm{~m}^{2}$ y que acoge a trescientas cincuenta personas.

Toma como base el planteamiento de "lotes en altura" que permite la configuración de soportes en dos niveles, con posibilidades de crecimiento interno mediante la subdivisión en alturas del espacio interior.

Para el establecimiento del soporte se ha de determinar previamente unos patrones habitacionales, fruto del estudio del entorno. En México existen unas zonas residenciales denominadas "vecindades", que parten de la agrupación en torno a patios de viviendas plurifamiliares. Estas vivien- das frecuentemente son casonas coloniales habitadas por varias unidades familiares de pocos recursos. Las casa coloniales suelen tener el espacio interior dividido mediante una entreplanta, lo que facilita la ampliación de la superficie habitable interior.

En relación con estas vecindades se obtiene como patrón habitacional espacios a doble altura, que ofrecerían posteriormente la posibilidad de ampliación mediante subdivisión del espacio interior. La ubicación de la escalera interna y los baños se dejan a la elección de los usuarios.

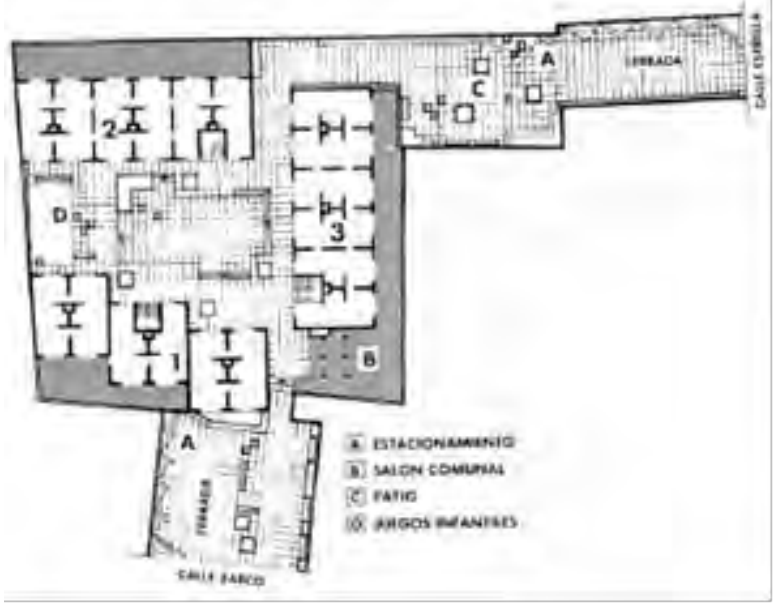




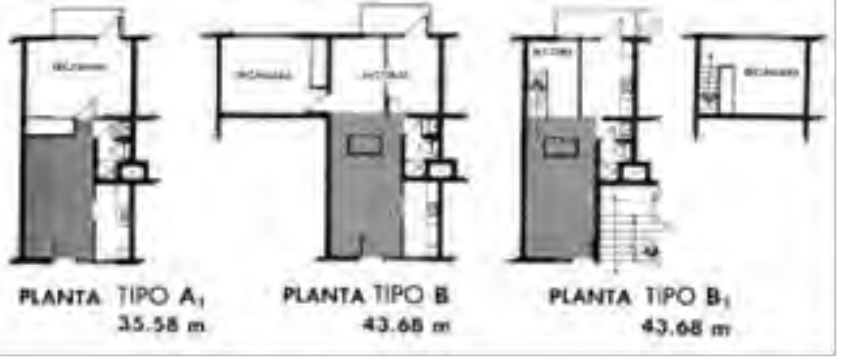

Figura 18. Viviendas Cooperativa Guerrero. México DF. Fuente: Jorge Andrade

\section{Diagoon Houses. Herman Hertzberger. Delf, Holanda. 1967 -1970}

\section{Vivienda ampliable, vivienda transformable}

Estas viviendas están diseñadas para proporcionar una alternativa, entregando el control del diseño al ocupante. Éste es capaz de decidir cómo compartimentar el espacio y vivir en él, donde va a dormir y donde va a comer. Si la composición de los miembros de un núcleo familiar varía, la casa puede ser modificada, ajustada y ampliada.

La vivienda básicamente consiste en dos núcleos encajados con semi-alturas que pueden acomodar distintas configuraciones. No hay separación estricta entre las zonas de día y noche, y en cada nivel el usuario puede introducir particiones para organizar el espacio a su gusto. Hertzberger propone un esqueleto estructural que puede ser completado por los usuarios de acuerdo a sus propias necesidades y deseos. Existen dos núcleos fijos, uno contiene la escalera y el otro, la cocina y el baño en diferentes niveles. Una planta tipo muestra la vivienda seccionada en cuatro niveles. La primera de ellas puede contener la entrada de la casa, un cuarto de trabajo, almacenamiento y un garaje pequeño o más grande. Subiendo un piso y medio, la cocina es el punto central, alrededor del cual se deja espacio para la interpretación: ¿Dónde se sitúa el comedor y cómo es de grande?, ¿Cómo se configura la sala de estar y cómo se relaciona con el balcón? La siguiente planta hacia arriba, es un piso entero por encima del nivel de entrada. El cuarto nivel se agrupa alrededor de un cuarto de baño alrededor de la cual el espacio puede ser dividido en habitaciones individuales o bien dejarse abierto. EI espacio inacabado se expresa con la aparición de algunos espacios exteriores relativamente ambiguos. ¿Cómo pueden los pequeños espacios debajo de la terraza utilizarse?, ¿Qué hacer con la terraza o el patio pequeño junto a la entrada? Con el tiempo estos espacios comodín pueden apropiarse y ser utilizados de diversas maneras. A pesar de su apertura y flexibilidad, las Casas Diagoon no son sólo edificios neutrales que ofrecen un número infinito de opciones, sino que proporcionan un marco de indicaciones sobre las posibilidades de disposición espacial que existen. El principio de estas casas se basa en la idea de la construcción incompleta, lo que significa que se deja espacio para la interpretación personalizada del usuario en relación al número de habitaciones, distribuciones y usos funcionales. Hertzberger ilustra las posibilidades de los espacios a través de diagramas, indicando las posibilidades inherentes de la casa. (Hertzberger, 1991), (Hertzberger, 1978), (Schneider, 1994).

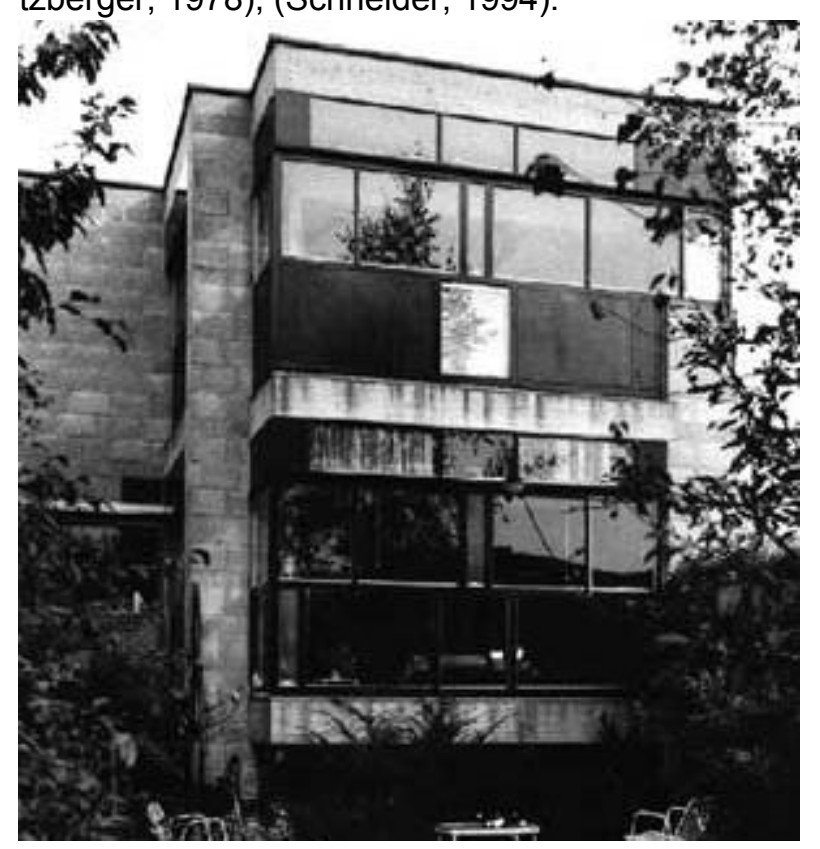

Figura 19: Alzado de Diagoon House. Delf. Holanda. Fuente:

<http://faculty.virginia.edu/GrowUrbanHabitats/case _studies/case_study_010127.html> 


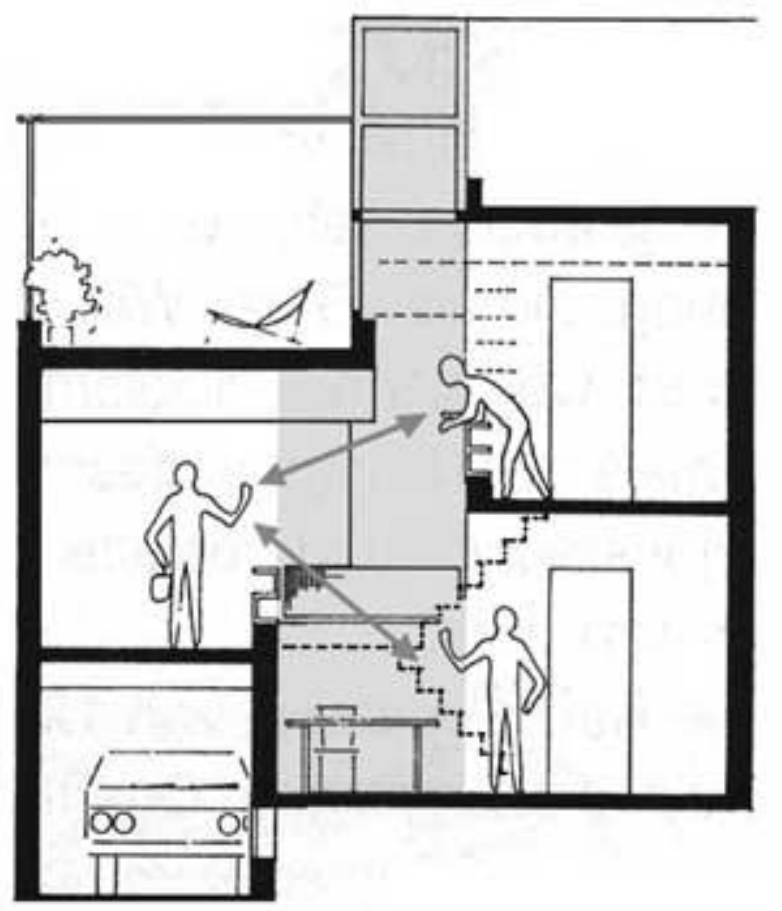

Figura 19 y 20: Sección de Diagoon House. Delf. Holanda. $\quad$ Fuente: <http://faculty.virginia.edu/GrowUrbanHabitats/case _studies/case_study_010127.html>

\section{Sargfabrik. BKK-3 Viena. Austria. 1992-1996}

\section{Vivienda desjerarquizada, vivienda cooperativa}

Casi desde una postura de activismo político, el colectivo de arquitectos BKK-3 propone una arquitectura de participación con el usuario y con las instituciones. Herederos de la amplia tradición vienesa de cooperativas de vivienda, que se remonta a los conocidos "höffe" de la década de 1920 , su obra hace un especial hincapié en nuevos modos de vida colectiva, dotando a los grupos de vivienda de una serie de servicios que refuercen el sentido de comunidad de los habitantes. Sargfabrik, se levanta en el emplazamiento de una antigua fábrica de ataúdes.

BKK-3 se opone a la práctica paternalista que desarrollaba el proceso de planificación a través de una serie de decisiones verticales que no tienen en cuenta a los usuarios finales y ofrecen el ideal de una planificación de abajo a arriba: su inspiración se basaba en las necesidades concretas de sus usuarios, que posteriormente se trasladaban a una forma espacial y organizativa. Sargfabrik se convirtió en un manifiesto de esta idea de planificación participativa, y para ello se estableció un sistema de consultas donde cada usuario tenía un número limitado de horas.

La superficie destinada a instalaciones comunes en edificios de vivienda social era del $10 \%$ total de la superficie del proyecto. Sin embargo, las instalaciones comunes en Sargfabrik ascienden a más del $20 \%$ de la superficie neta total $(1800 \mathrm{~m} 2)$. Esto se consigue solicitando una subvención para un hogar residencial o albergue ya que permite un mayor porcentaje de zonas comunes. Se produce así, un cambio de lenguaje pasando de apartamentos a hogares, de café a cocina del albergue, de piscina a duchas colectivas, de sala de conciertos a sala de música, de guardería a sala de juegos.

Con este proyecto, BKK-3 formula una crítica explícita al discurso del Movimiento Moderno sobre la vivienda, tanto desde el punto de vista arquitectónico como de planificación urbanística. Entre sus objetivos se encontraba la idea de una forma de vida potenciada por un mayor número de funciones colectivas.

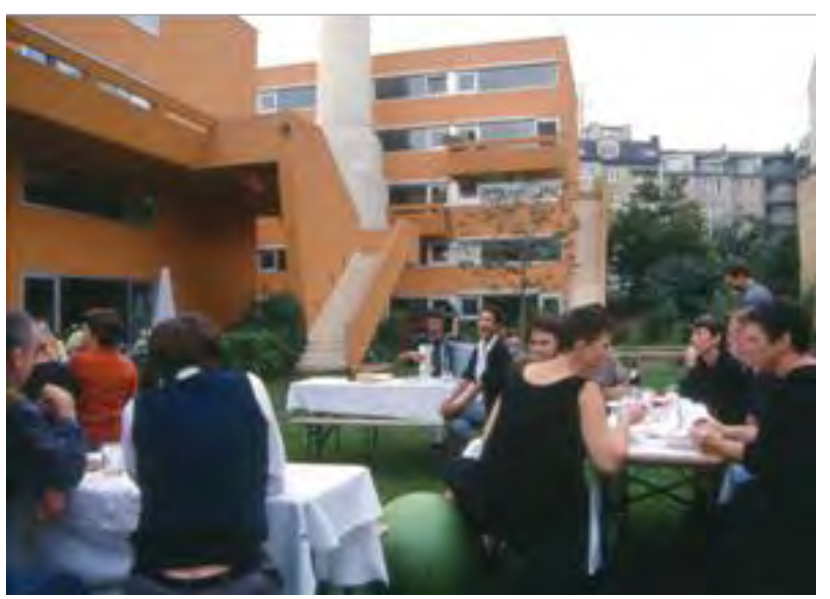

Figura 21: Sargfabrik. Viena. Fuente: BKK-3 Architektur ZT-GmbH. 


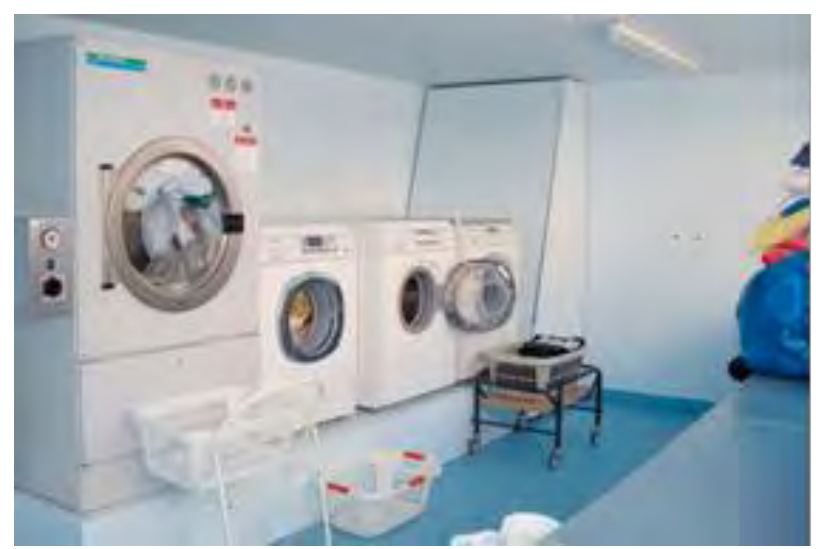

Figura 22: Sargfabrik. Viena. Fuente: BKK-3 Architektur ZT-GmbH.

\section{Casa más o menos. Lapanadería. Alcalá de Guadaira, 2007}

\section{Vivienda perfectible, vivienda transformable}

Se trata de un edificio de ocho apartamentos en el que al usuario se le hace partícipe del proceso de diseño y finalización de su vivienda, definiendo qué grado de acabado quiere o puede pagar. Éste puede personalizarla en función de su idea de vivienda, necesidades o economía con una casa "más o menos terminada".

Las viviendas se ponen en venta a través de una página web en la que el usuario podía conocer al detalle cada una de las viviendas y los diferentes grados de acabados que se ofrecían (+o -). En cada caso, se le plantea al cliente una serie de opciones sobre diferentes aspectos de la vivienda. A partir de una opción base, cada uno podía añadir o quitar elementos con el incremento o disminución del precio final de la vivienda que cada decisión conllevaba. La opción base fue la más elegida por los usuarios. Los acabados de esta posibilidad están suficientemente en bruto cómo para que cada uno tenga margen para transformarla y mejorarla según sus gustos.

El objetivo era poner en práctica estrategias y herramientas (tanto de diseño, como constructivas, de gestión y económicas) que permiten abrir los procesos de definición de la vivienda, posibilitando la interacción y participación del usuario.
La participación del usuario se produce en la fase de diseño gracias a la estrategia tipológica propuesta por los arquitectos, la voluntad del promotor y un programa informático que permite seleccionar los diferentes grados de acabados de las viviendas.

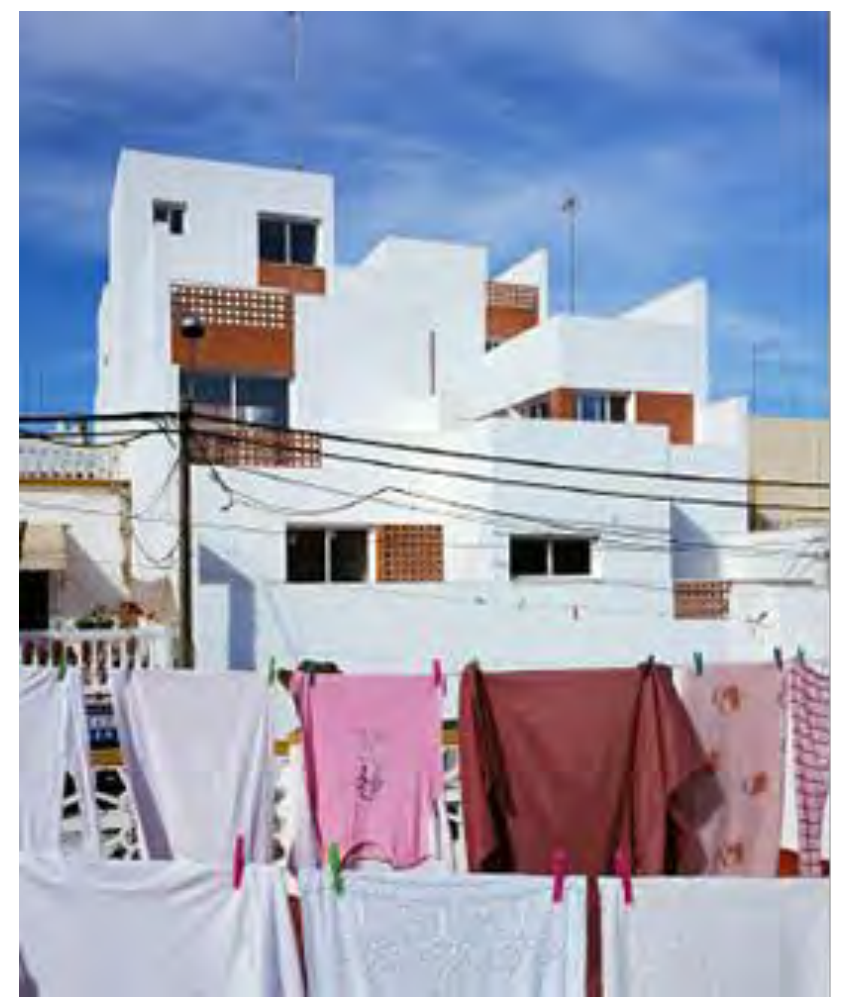

Figura 23: Fachada "casa más o menos". Alcalá de Guadaíra. Sevilla. Fuente: lapanaderia S.L.P. http://www.despachodepan.com

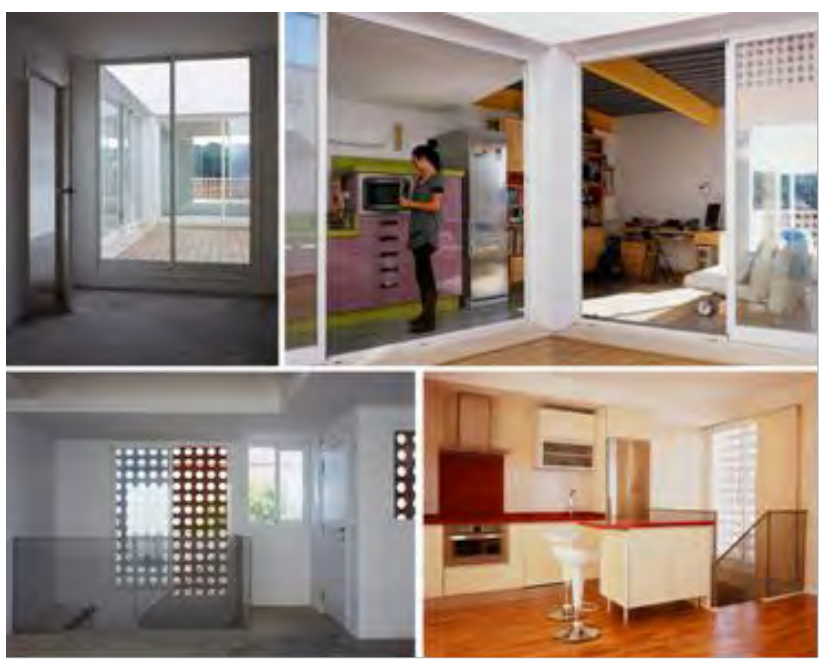

Figura 24: Apropiación de las viviendas por los distintos usuarios. "Casa más o menos". Alcalá de Guadaíra. Sevilla. Fuente: lapanaderia S.L.P. <http://www.despachodepan.com> 


\section{Referencias}

BEISI, J. Adaptable housing or adaptable people? Architecture \& Behaviour (Swiss Federal Institute of Technology), 1995, no 11, p.139-162.

HEIDEGGER, M. Construir, habitar, pensar. Conferencias y artículos. ( $2^{\mathrm{a}}$ ed. rev.). Barcelona: Ediciones del Serbal, 2001.

FERRERO, J. La vivienda evolutiva. Revista Vivienda Popular, 1998, $\mathrm{n}^{\circ} 3$.

GONZÁLEZ LOBO, C. Vivienda y ciudad posibles. Bogotá: Ed. Escala / Col. Tecnologías para vivienda de interés social, vol. 4, 1998.

HABRAKEN, N.J. Soportes: Una alternativa al alojamiento de masas. Barcelona: Ed. Gustavo Gili, 1975.

HERTZBERGER, H. Lessons For Students In Architecture. (I.Rike, Trans.) Rotterdam, The Netherlands: 010 Publishers, 1991.

HERTZBERGER, H. Maisons "Diagoon", Delft. Architecture d'aujourd'hui, 1978, n 196, p. 2023.

LEUPEN, B. Polyvalence, a concept for the sustainable dwelling. Nordic journal of architectural research, 2006b, vol.19, n 3 .

LORENZO, P. Un techo para vivir: tecnologías para viviendas de producción social en América Latina. Barcelona: Ediciones UPC, 2005.

MORIN, E. La mente bien ordenada. Barcelona: Seix Barral, 2007.

ORTIZ FLORES, E. Integración de un sistema de instrumentos de apoyo a la producción social de vivienda. México: Coalición Internacional para el Hábitat (HIC-AL), 2007.

PARICIO, I. y SUST, X. La vivienda contemporánea. Programa y tecnología. Barcelona: Instituto de la Tecnología de la Construcción de Cataluña (ITeC), 2000.

PELLI, V. Del campo a la ciudad. La comunidad que surgió de una experiencia. In GRUPO VIVIENDA SEMILLA. Vivienda Latinoamericana. Tecnología y participación social en la construc- ción del hábitat popular. Santiago de Chile: Programa Red Cyted-D/ XIV, 1991.

PELLI, V. Clarificación y Replicabilidad: la aplicación masiva de los procedimientos progresivos y participativos de vivienda. Pobreza Urbana $y$ Desarrollo, 1992, año 1, n¹, p. 86-97.

PELLI, V., LUNGO, M., ROMERO G., BOLÍVAR, T. Reflexiones sobre la autoconstrucción del hábitat popular en América Latina. América Latina: Programa Red Cyted XIV-B, 1994.

RAMÓN MOLINER, F. Alojamiento. Madrid: Ed. Cambio 16, 1976.

SCHMIDT, R.; EGUCHI, T.; AUSTIN, S.; ALISTAIR, G. What is the meaning of Adaptability in the Building Industry? In CHICA, ELGUEZABAL, MENO y AMUNDARAIN (Eds.). O\&SB2010 16th International Conference: Open and Sustainable Building. Bilbao, 2010. <http://cibworld.xs4all.nl/dl/publications/w104_16 th.pdf> (Consultado el 18 de febrero de 2012).

SCHNEIDER, F. (ed.). Grundrißatlas Wohnungsbau - Floor plan atlas: housing. Basel: Birkhäuser, 1994.

SCHNEIDER, T. y TILL, J. Flexible housing: opportunities and limits. Architectural Research Quarterly, 2005a, n 9, p.157-166.

SCHNEIDER, T. y TILL, J. Flexible housing: the means to an end. Architectural Research Quarterly, 2005b, nº 9 (3-4), p.287-296.

TURNER, J.F.C. La vivienda, todo el poder para los usuarios. Madrid: Editorial Blume, 1977.

\section{Cita del artículo}

MORALES SOLER, E., ALONSO MALLÉN, R. Y MORENO CRUZ, E.. La vivienda como proceso. Estrategias de flexibilidad. Hábitat y Sociedad, 2012, nº 4, p. 33-54. <www.habitatysociedad.us.es>.

http://dx.doi.org/10.12795/HabitatySociedad.2012.i4.03 